\title{
SYNTHESIS OF MESOPOROUS SILICA SBA-15 THROUGH SURFACTANT SET-UP AND HYDROTHERMAL PROCESS
}

\author{
R. Thahir ${ }^{1, *}$, A. W. Wahab ${ }^{2}$, N. L. Nafie ${ }^{2}$ and I. Raya ${ }^{2}$ \\ ${ }^{1}$ Department of Chemical Engineering, Politeknik Negeri Ujung Pandang, Makassar-90254, \\ South Sulawesi, Indonesia \\ ${ }^{2}$ Department of Chemistry, Faculty of Mathematics and Natural Science/Hasanuddin University, \\ Makassar-90245, South Sulawesi, Indonesia \\ *E-mail: ridha331@poliupg.ac.id
}

\begin{abstract}
The purpose of this study was synthesizing mesoporous silica SBA-15 and investigated the effect of the initial temperature of the preparation surfactant using the hydrothermal process to synthesize silica SBA-15. Pluronic (P123) as surfactant template and TEOS as material precursor acted as a building block of the mesoporous silica material. Therefore, the interaction surfactant template and precursor during the hydrothermal process guided to silica SBA-15 properties. The results suggested that the physicochemical properties of these materials did not change significantly, but different condition temperature of surfactant and hydrothermal process affected the size of the specific surface area, pore volume, and pore size distribution. The largest specific surface area was $560 \mathrm{~m}^{2} \mathrm{~g}^{-1}$, pore volume was $1.57 \mathrm{~m}^{3} \mathrm{~g}^{-1}$ and ordered pore size distribution around $11.24 \mathrm{~nm}$ after the initial temperature of the surfactant at $15^{\circ} \mathrm{C}$ and hydrothermal process at $100^{\circ} \mathrm{C}$ for $48 \mathrm{~h}$. This resulted properties of SBA-15 are potentially applicable in various chemical and non-chemical based industries.
\end{abstract}

Keywords: Silica SBA-15, Mesoporous, Surfactant, Hydrothermal process, Precursor

(C) RASĀYAN. All rights reserved

\section{INTRODUCTION}

Porous materials, as specified by IUPAC nomenclature are described as a solid consist of pores and have a porosity of 0.2 to 0.95 that fractionate of pores to the total volume ${ }^{1}$. SBA- 15 is one of the mesoporous material from silica source that having uniform pore size with periodic of widths 50 to $300 \AA$ and use of amphiphilic block copolymer as structure directing agent ${ }^{2}$. This material has excellent structure, such as a large specific surface area, large pore volume, array ordered hexagonal mesostructure that makes it widely used in the many practical application as catalyst support ${ }^{3,4}$, an adsorbent ${ }^{4-7}$, an immobilization substrate for biomolecules ${ }^{8,9}$ and chemical sensor ${ }^{10,11}$. For the most industrial application of mesoporous material, the large surface area is important for catalysis. The surface area of the solid interacts with its surroundings can be it liquid, gas or solid in solution. As the surface area increases, the mechanical strength and thermal stability may be decreased. The fine properties of SBA-15 include large surface area and high mechanical strength. Both properties should be obtained by the synthesized material for further application as an adsorbent and catalyst ${ }^{12,13}$.

The main factors affecting mesoporous silica SBA-15 are some variable synthesis condition such as $\mathrm{pH}$, using of catalyst, hydrolysis and condensation process, the aging and drying condition ${ }^{14}$, surfactant template, co-solvent, micelle expander ${ }^{15}$, and removal process of surfactant ${ }^{16}$. The synthesis of SBA-15 is simple, where the surfactant formed in solution then hydrolyzed and condensed to prepare sol-gel. Mesoporous silica with the large ordered porous of silica SBA-15 $\left(S_{\text {BET }} 580 \mathrm{~m}^{2} \mathrm{~g}^{-1} ; \mathrm{V}_{\mathrm{t}} 1.32 \mathrm{~cm}^{3} \mathrm{~g}^{-1}\right)$ has been studied by many researchers using triisopropyl benzene as a swelling agent with hexagonal structure have been synthesized, the tuning of the initial temperature of surfactant template, and the hydrothermal set-up time ${ }^{14}$. Accordingly, in this research, the experimental variables such as the preparation surfactant

Rasayan J. Chem., 12(3), 1117-1126(2019)

http://dx.doi.org/10.31788/RJC.2019.1235306

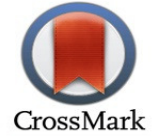


template and hydrothermal process were utilized to investigate the change in mesostructure and physisorption analysis of silica SBA-15.

For that reason, to develop novel techniques, this study was aimed to improve the properties of mesoporous materials would be of great concent for current applications. In this work, we evaluate another preparation process of surfactant template through a hydrothermal process that can arrange the mesopore and explain clearly the physisorption analysis by the BET method and characterization by Xray diffraction (XRD), Fourier transforms infrared spectroscopy (FTIR), and differential scanning calorimetry (DSC).

\section{Material and Methods}

\section{EXPERIMENTAL}

All the chemical reagents Pluronics (P123, Poly(ethylene glycol)-block-poly(propylene glycol)-blockpoly(ethylene glycol), average $M_{n} \sim 5800$ ), tetraethyl orthosilicate (TEOS, 98\%) were used analytical grade without purification and purchased from Sigma-Aldrich, hydrochloric acid ( $\mathrm{HCl}, 37 \%)$ from Merck, ammonium fluoride $\left(\mathrm{NH}_{4} \mathrm{~F}\right)$, and heptane were obtained from J.T. Baker.

\section{General Procedure}

\section{Preparation of Mesoporous Silica SBA-15}

Various methods have been developed and introduced to prepared mesoporous silica materials SBA-15 was synthesized using a method proportional to that reported previous ${ }^{15}$, but TMOS was substituted with TEOS and triisopropyl benzene was substituted with heptane. In a typical procedure, initial step $2.4 \mathrm{~g}$ of Pluronic 123 as surfactant template and $\mathrm{NH}_{4} \mathrm{~F}(0.027 \mathrm{~g})$ were dissolved in $84 \mathrm{ml} \mathrm{HCl} 1.3 \mathrm{M}$. The mixture was stirred at $30^{\circ} \mathrm{C}$ until clear. The solution was transferred to the water bath and set at a temperature $\mathrm{T}_{1}$ as the initial temperature of preparation surfactant template, $\left(T_{1}=10^{\circ} \mathrm{C}\right.$ for samples $\mathrm{C}$ and $\mathrm{D} ; \mathrm{T}_{1}=15^{\circ} \mathrm{C}$ for samples A and B) at any rate at $1 \mathrm{~h}$. Then, the other solution of $3.7 \mathrm{ml}$ of TEOS as a silica source and 1.2 $\mathrm{mL}$ of heptane was added. The mixture was stirred for $24 \mathrm{~h}$ at $30^{\circ} \mathrm{C}$ in an open container. After that, the solution was transferred to a closed Teflon container for the hydrothermal process at temperature $\left(\mathrm{T}_{2}=\right.$ $100^{\circ} \mathrm{C}$ for samples $\mathrm{A}$ and $\mathrm{B} ; \mathrm{T}_{2}=120^{\circ} \mathrm{C}$ for samples $\mathrm{C}$ and $\mathrm{D}$ ). The time of hydrothermal treatment, $\mathrm{t}=48$ $\mathrm{h}$ for samples A and C; $t=96 \mathrm{~h}$ for samples B and D. After that, it was cooled to room temperature. The gel white products were filtered and washed with deionized water repeatedly until $\mathrm{pH} 7$ was obtained. Finally, the results were dried at $60^{\circ} \mathrm{C}$ for $24 \mathrm{~h}$ and then calcined at $550^{\circ} \mathrm{C}$ for $5 \mathrm{~h}$.

\section{Variables of The Experiment}

There are two variables dependent on this experiment. They are the initial temperature of the surfactant template $\left(\mathrm{T}_{1}=10\right.$ and $\left.15^{\circ} \mathrm{C}\right)$ and process condition of hydrothermal treatment $\left(\mathrm{T}_{2}=100\right.$ and $120^{\circ} \mathrm{C}$ for the aging time $=48$ and $96 \mathrm{~h}$ ). The combining variables $\mathrm{T}_{1}, \mathrm{~T}_{2}$, and the aging time of samples were labeled as SBA-15 A, B, C, and D. In Table-1 typical variable dependent of sample SBA-15

Table-1: A Typical Variable of the Experiment

\begin{tabular}{c|c|c|c}
\hline SBA-15 Sample & $\mathrm{T}_{1}\left({ }^{\circ} \mathrm{C}\right)$ & $\mathrm{T}_{2}\left({ }^{\circ} \mathrm{C}\right)$ & Aging Time (hour) \\
\hline $\mathrm{A}$ & 15 & 100 & 48 \\
\hline $\mathrm{B}$ & 15 & 100 & 96 \\
\hline $\mathrm{C}$ & 10 & 120 & 48 \\
\hline $\mathrm{D}$ & 10 & 120 & 96 \\
\hline
\end{tabular}

\section{Characterization of Silica SBA-15}

The physisorption analysis was measured using a Quantachroma NovaWin instruments version 11.0 at temperature $-196^{\circ} \mathrm{C}$. Before the experiments were measured, the samples were degassed under vacuum at $300^{\circ} \mathrm{C}$ for $3 \mathrm{~h}$. The total pore volume was determined from the amount adsorbed at relative pressure 0.98 . Pore size distribution (PSD) was calculated from adsorption data using the Barrett-Joyner-Halenda (BJH) method. The total specific surface area $\left(\mathrm{S}_{\mathrm{BET}}\right)$ was calculated in the relative pressure range from 0.02 to 0.3 using the multi-point BET method. ${ }^{17,18}$ X-ray diffraction (XRD) was used to identify the crystal phase of silica SBA-15. The experiments were performed on a Bruker D2 Phaser Diffractometer System with 
RASĀYAN J. Chem.

Vol. 12 | No. 3 |1117 - 1126| July - September | 2019

$\mathrm{CuK} \alpha$ radiation source $1.5406 \AA$ run at $40 \mathrm{kV}, 30 \mathrm{~mA}$. XRD patterns were obtained with wide angles from $10-70^{\circ}$ of $2 \theta$, with a step size of $0.02^{\circ}$ and the time step of $1 \mathrm{~s}$. Differential scanning calorimeter, DSC-60Plus Shimadzu was measured thermoanalytical properties of SBA-15. DSC measurement technique was determined from physical transformation and thermal histories such as the glass transition, the crystallization point, and melting point of materials. The sample was put in Al crimp pan S201-52943 types and sits upon a constant disc on the frame in the DSC analysis cell. Temperature range from 20 to $250^{\circ} \mathrm{C}$ for $20 \mathrm{~min}$. Prestige-21 Shimadzu Infrared spectroscopy was used to identify the various functional group and different types of bonding $\mathrm{SiO}_{2}$ materials in range $400-4000 \mathrm{~cm}^{3}$ using $\mathrm{KBr}$ pellet.

\section{RESULTS AND DISCUSSION}

The pattern of mesoporous silica SBA-15 can be prepared to identify the properties of mesoporous silica SBA-15. The pore size can be tuned from 9 to $14 \mathrm{~nm}$, pore volume from 1.4 to $1.8 \mathrm{~cm}^{3} / \mathrm{g}$ and surface area from 450 to $560 \mathrm{~m}^{2} / \mathrm{g}$. Also, different morphologies were obtained if the variation synthesized condition of silica SBA-15. In order to explain the surface area and the physicochemical properties SBA-15, a series experiment was conducted to understand the effect of the preparation surfactant template using hydrothermal treatment.

\section{Physical Adsorption Analysis of Silica SBA-15}

Several important for the physical adsorption analysis of mesoporous silica SBA-15 are long distance with mesostructure, the distribution of pore size is mostly tight, large specific surface area and the size of pore diameter can differ from 9 to $14 \mathrm{~nm}^{19}$. Nitrogen adsorption-desorption isotherm is a physical sorption analysis to determine the total specific surface area $\left(\mathrm{S}_{\mathrm{BET}}\right)$, pore volume, and pore size distribution of a solid. ${ }^{20}$ The Brunauer-Emmett-Teller (BET) method is the physical sorption of the amount adsorbed on a solid surface at the relative pressure $\mathrm{P} / \mathrm{P}_{\mathrm{o}}$ at a constant temperature. The $\mathrm{BET}$ equation is a guidance for analysis technique to determine the total specific surface area of materials ${ }^{21}$. The pore size distribution (PSD) determined by using nitrogen adsorption data ${ }^{22}$ and calculated by the BJH method. ${ }^{23}$

This study investigates the effects of the preparation temperature of the surfactant template and hydrothermal treatment to synthesize SBA-15. For that reason, our experiment has combined some variables to evaluate the specific surface area, pore size distribution, and pore volume of silica SBA-15 whether it is microporous, mesoporous or macroporous.

Table-2: Surface Analysis of SBA-15 Samples with Some Variables

\begin{tabular}{c|c|c|c|c}
\hline $\begin{array}{c}\text { SBA-15 } \\
\text { sample }\end{array}$ & Conditions & $\begin{array}{c}\mathrm{S}_{\mathrm{BET}} \\
\left(\mathrm{m}^{2} \cdot \mathrm{g}^{-1}\right)^{\mathrm{a}}\end{array}$ & $\begin{array}{c}\mathrm{Dp} \\
(\mathrm{nm})^{\mathrm{b}}\end{array}$ & $\begin{array}{c}\mathrm{Vp} \\
\left(\mathrm{cc} \cdot \mathrm{g}^{-1}\right)^{\mathrm{c}}\end{array}$ \\
\hline $\mathrm{A}$ & $\left(\mathrm{T}_{1}=15^{\circ} \mathrm{C}, \mathrm{T}_{2}=100^{\circ} \mathrm{C}\right) ; \mathrm{t}=48 \mathrm{~h}$ & 560 & 11.24 & 1.57 \\
\hline $\mathrm{B}$ & $\left(\mathrm{T}_{1}=15^{\circ} \mathrm{C}, \mathrm{T}_{2}=100^{\circ} \mathrm{C}\right) ; \mathrm{t}=96 \mathrm{~h}$ & 554 & 12.67 & 1.44 \\
\hline $\mathrm{C}$ & $\left(\mathrm{T}_{1}=10^{\circ} \mathrm{C}, \mathrm{T}_{2}=120^{\circ} \mathrm{C}\right) ; \mathrm{t}=48 \mathrm{~h}$ & 510 & 13.76 & 1.76 \\
\hline $\mathrm{D}$ & $\left(\mathrm{T}_{1}=10^{\circ} \mathrm{C}, \mathrm{T}_{2}=120^{\circ} \mathrm{C}\right) ; \mathrm{t}=96 \mathrm{~h}$ & 548 & 8.97 & 1.49 \\
\hline
\end{tabular}

${ }^{\mathrm{a}}$ total $\mathrm{BET}$ surface area; ${ }^{\mathrm{b}}$ pore diameter determined from BJH method; ${ }^{\mathrm{c}}$ total pore volume

A Case study approach was used to allow a physical adsorption analysis to obtain the characteristic of the mesoporous material. A quantitative analysis data of silica SBA-15, such as specific surface area, pore volume, pore size distribution, and pore diameter were greatly affected by the various condition process. The preparation of the surfactant template and hydrothermal process were both investigated to explain the properties of silica SBA-15.

Table-2 compares the experimental data for various condition process of synthesized silica SBA-15 on physisorption analysis. It can be seen from Table-2, the total BET surface area of the silica SBA-15 gained from different temperature process and the time of the hydrothermal process. Sample A and B were prepared with the same temperature process, but different from the time hydrothermal treatment. The total BET surface area of Samples A as well as the pore volume was larger than Sample B. However, Samples C and D synthesized for the same temperature process, but Sample D had longer the time of 
hydrothermal treatment. A positive correlation was found between the temperature process and the time of hydrothermal treatment. Post hoc analysis revealed that during the preparation of the surfactant template, the formation of the micelles from surfactant agent was based on the synthesis of mesoporous materials. ${ }^{24}$

Overall, these results indicate that the temperature of the preparation process is one type $\left(\mathrm{T}_{1}=15^{\circ} \mathrm{C}\right.$, $\mathrm{T}_{2}=100^{\circ} \mathrm{C}$ ) if the shorter of the time hydrothermal treatment is chosen. In order part, another important finding was that the temperature preparation process $\left(\mathrm{T}_{1}=10^{\circ} \mathrm{C}, \mathrm{T}_{2}=120^{\circ} \mathrm{C}\right)$ were obtained the larger pore volume and pore diameter but the lower of the surface area. As mentioned in the previous study, the interaction between surfactant as a directing agent and silica source is the building block of mesoporous materials properties. ${ }^{14,25,26}$

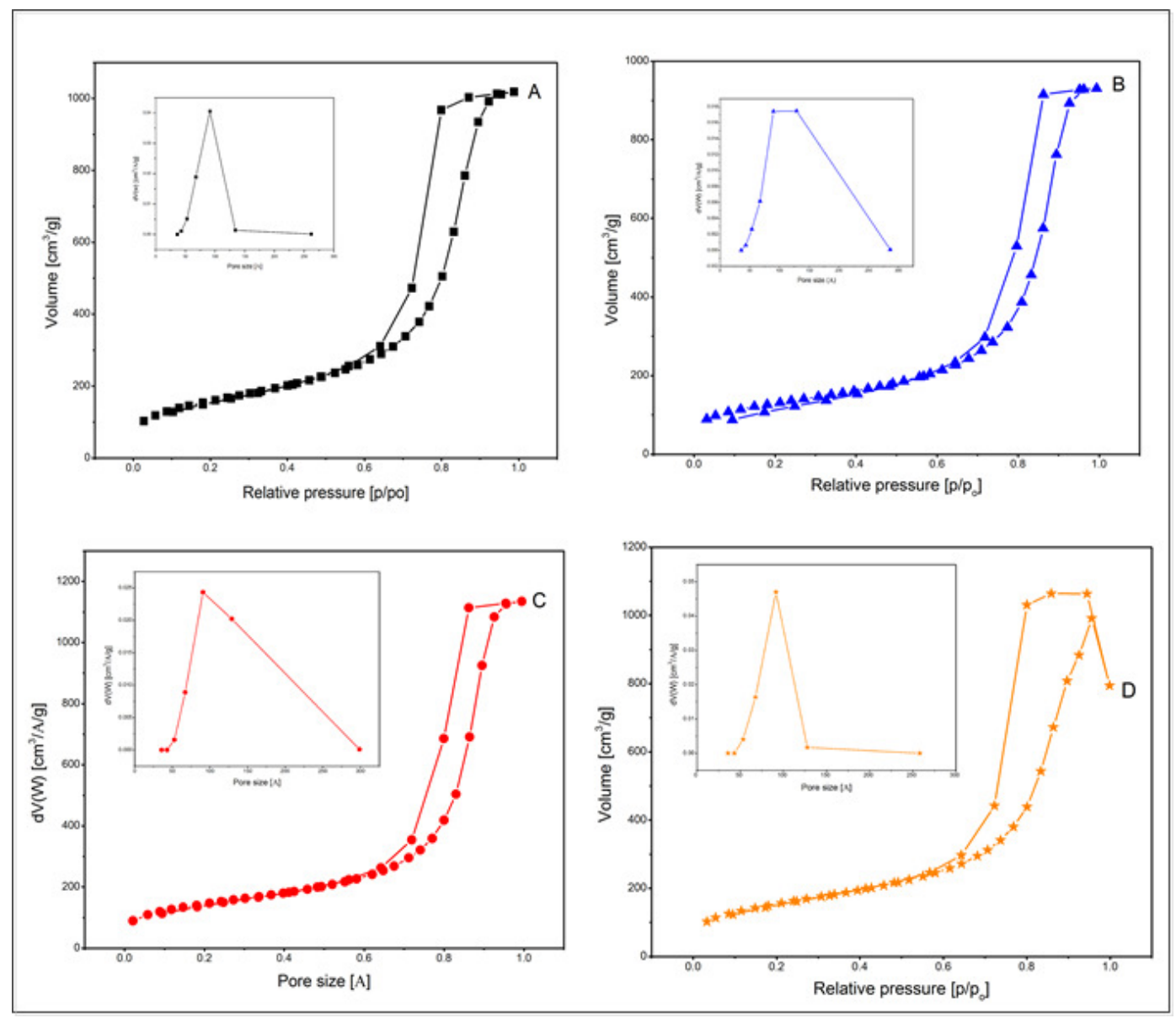

Fig.-1: $\mathrm{N}_{2}$ Adsorption Isotherm of SBA-15 Samples and BJH Pore Size Distribution (Inner Figure)

From Fig.-1, that nitrogen physisorption isotherm analysis for all silica SBA-15 samples represented the same adsorption isotherm trend which indicated that the samples are almost ideally mesoporous materials. The characteristic shape of SBA-15 samples is near in theory type-IV with H1-type of hysteresis loop according to IUPAC classification ${ }^{17,27}$, no significant change with the different variable condition synthesized of SBA-15. The nitrogen sorption isotherms for the samples exhibited step sharp in the $\mathrm{p} / \mathrm{p}_{\mathrm{o}}$ range from 0.7 to 0.9 , showing the presence of large porous to the capillary condensation ${ }^{28}$.

It can be seen that the same condition of the temperature preparation process, the pore size distribution of Sample A and Sample B is nearly the same (Fig.-1 and Table-2). However, the surface area and pore diameter of Sample D is significantly reduced than Sample B (Fig.-1 and Table-2). As can be explained that the time for hydrothermal treatment greatly affects the surface analysis. Both samples form interaction with P123 and TEOS is slowly during $96 \mathrm{~h}$ which can affect the formation of a large surface 
area for an initial temperature of $\mathrm{P} 123$ at $10^{\circ} \mathrm{C}$. The surface area of Sample A is the largest, but the lowest for pore diameter. The suitable surface analysis is listed in Table-2.

The pore volume for all the SBA-15 samples is high. The results obtained from a preliminary analysis of the amount of nitrogen adsorption in silica SBA-15 are presented in Figure 2. Sample $\mathrm{C}$ has the largest pore volume $\left(1.76 \mathrm{~cm}^{3} / \mathrm{g}\right.$ ), and pore volume for Sample B is less than $1.44 \mathrm{~cm}^{3} / \mathrm{g}$. Fig.-1 (inner figure) illustrates that the pore size distribution (PSD) is homogeneous, this in common with a Gaussian distribution, so the measurement of the width of the dispersion is direct the standard deviation ${ }^{25,29}$. It can be compared to Fig.-1 for all the samples, the PSD of Sample A and Sample D (pore diameter 50-180A) is lower than Sample B, and Sample C (pore diameter 50-300 $\AA$ ). Anyway, the most significant difference between the synthesis condition of the temperature of surfactant template for guiding the pore structure and hydrothermal treatment for interacting P123 as surfactant and TEOS as a precursor, even though not significant pore structure of Sample A, Sample B, and Sample C.
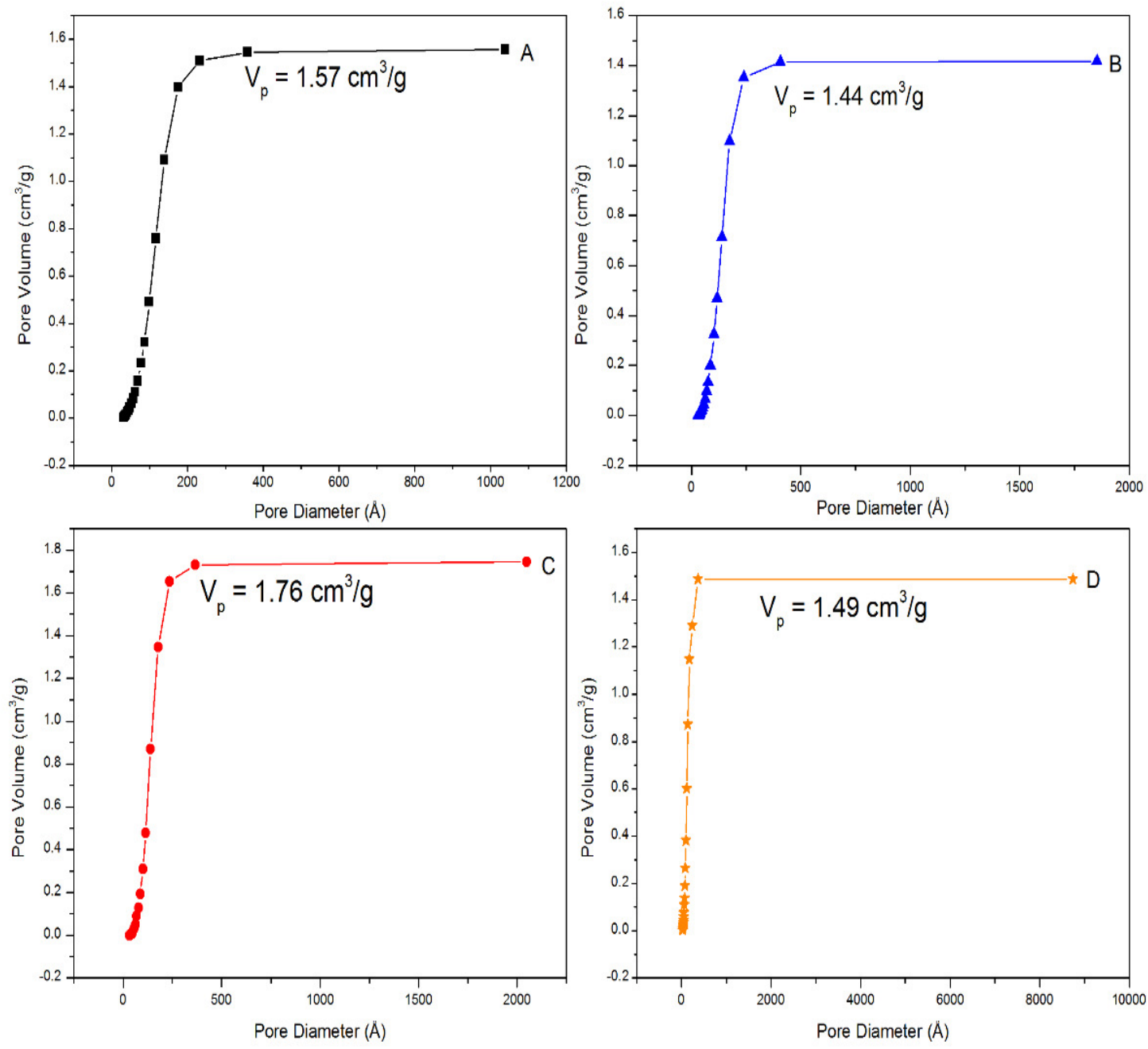

Fig.-2: Cumulative Pore Volume for SBA-15 Samples

Furthermore, to gain insight into the effect of aging time for hydrothermal treatment, Fig.-2, described that Sample A and Sample B was prepared in the same initial temperature $\left(15^{\circ} \mathrm{C}\right)$ and the same temperature of hydrothermal treatment $\left(100^{\circ} \mathrm{C}\right)$ but different of time aging. The PSD Sample B is slightly wider than Sample A, that the longer aging time of Sample B (96 hours) tunes ordered pore structure and more uniform pore size. This result suggests that the pore diameter can be ordered to a certain extent by increasing the duration of hydrothermal treatment. ${ }^{15,30}$ 


\section{Physicochemical Properties of Silica SBA-15}

In this regard, it is of great significance that the application of the most popular method to analysis the pore structure and physicochemical properties of silica SBA-15. The procedural step of the mesostructure of silica SBA-15 is established. The crystalline structure was determined using XRD, various functional groups by FTIR and thermal analysis by DSC. The wide angle X-ray diffraction (XRD) pattern of silica SBA-15 samples was used to identify the crystal phase of the samples. ${ }^{24,31}$

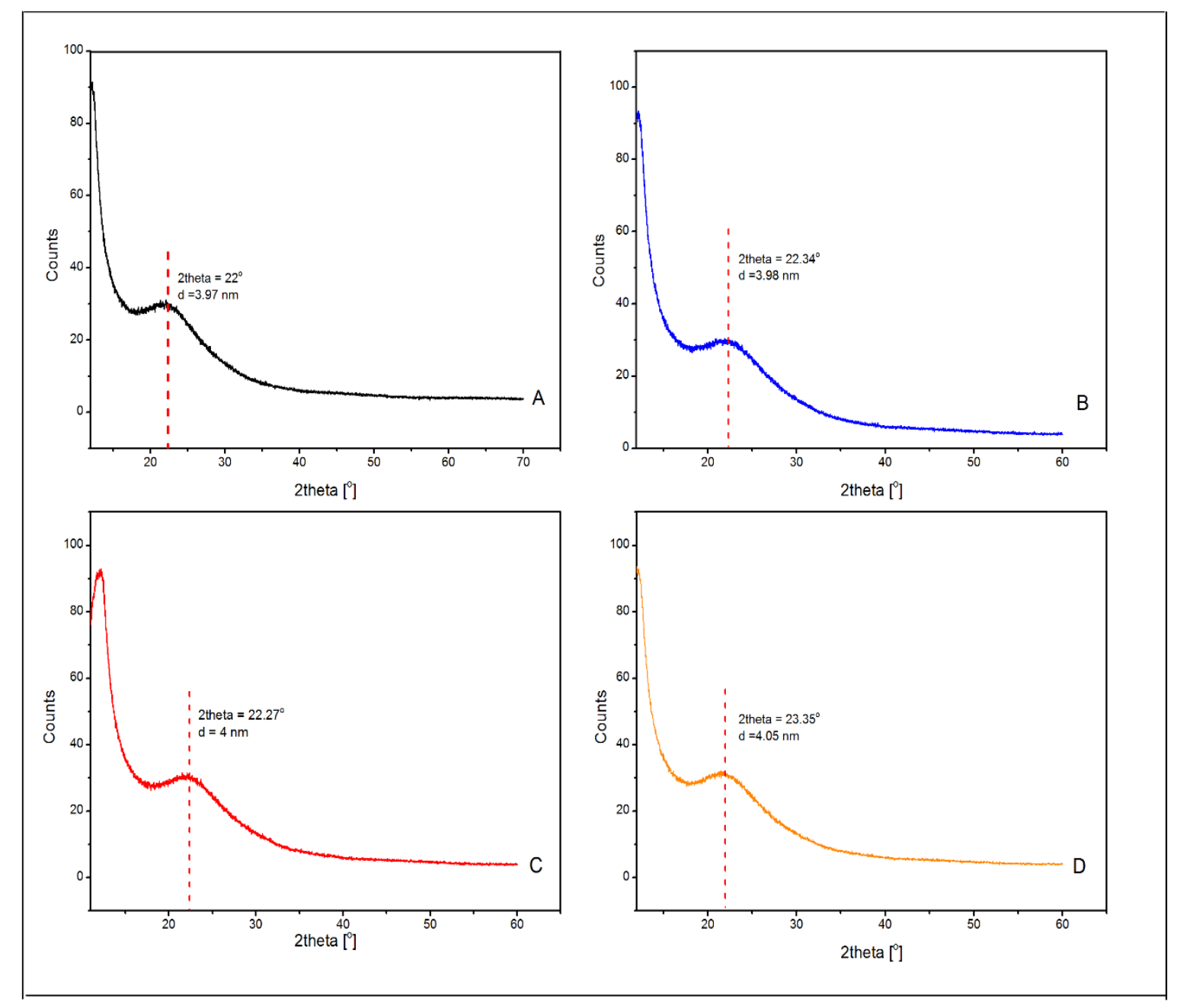

Fig.-3: XRD Pattern of Silica SBA-15 Samples

The pattern is shown in Fig.-3, there is one peak at $2 \theta$ of $23^{\circ}$, as reflection associated with p6mm space group and hexagonal symmetry mesostructure. The pattern XRD in Fig.-3 shows that the wide-angle XRD (WAXRD) of SBA-15 samples are a typical diffraction amorphous phase of silica SBA-15 ${ }^{32-34}$. From Fig.-3, it can be shown that interplanar spacing is nearly unchanged, although the preparation process is varied. Data from the XRD pattern can be compared with the data in Fig.-4 and Fig.-5, which shows conducive to expand silica materials.

Infrared spectroscopy identifies chemical bonds in a molecule by producing an infrared absorption spectrum for detecting functional groups and characterizing covalent bonding information. The FTIR spectra illustrate some of the main vibrational band of the silica material. According to the spectrum, wave number between $500 \mathrm{~cm}^{-1}$ to $4000 \mathrm{~cm}^{-1}$ represent the functional group of $\mathrm{Si}, \mathrm{O}$, and $\mathrm{H}^{24,35}$

Figure-4 shows the pattern of the SBA-15 samples gain almost the same and only different at the spectrum pattern. At peak $966-968 \mathrm{~cm}^{-1}$, the wave number suitable to connect $\mathrm{Si}-\mathrm{O}-\mathrm{Si}$ stretching. 
RASĀYAN J. Chem.

Vol. 12 | No. 3 |1117 - 1126| July - September | 2019

Broadband connects to represent the $-\mathrm{OH}$ groups $(\mathrm{Si}-\mathrm{OH})$ at peak $3445-3449 \mathrm{~cm}^{-1}$. Whereas, the peak observed at $1640-1645 \mathrm{~cm}^{-1}$ to indicate the presence of $-\mathrm{OH}$ groups $(\mathrm{H}-\mathrm{O}-\mathrm{H})$. Asymmetric Si-O-Si stretching happens at 1090-1103 $\mathrm{cm}^{-1}$. This result is in accord with Hesty's (2018) findings which observed removing surfactant template by calcination process ${ }^{34,36}$. At peak $801 \mathrm{~cm}^{-1}$, the wave number to connect symmetric Si-O-Si stretching. In fact, the analysis absorption peaks of SBA-15 samples, there is no change in spectrum bond analysis for all the samples.

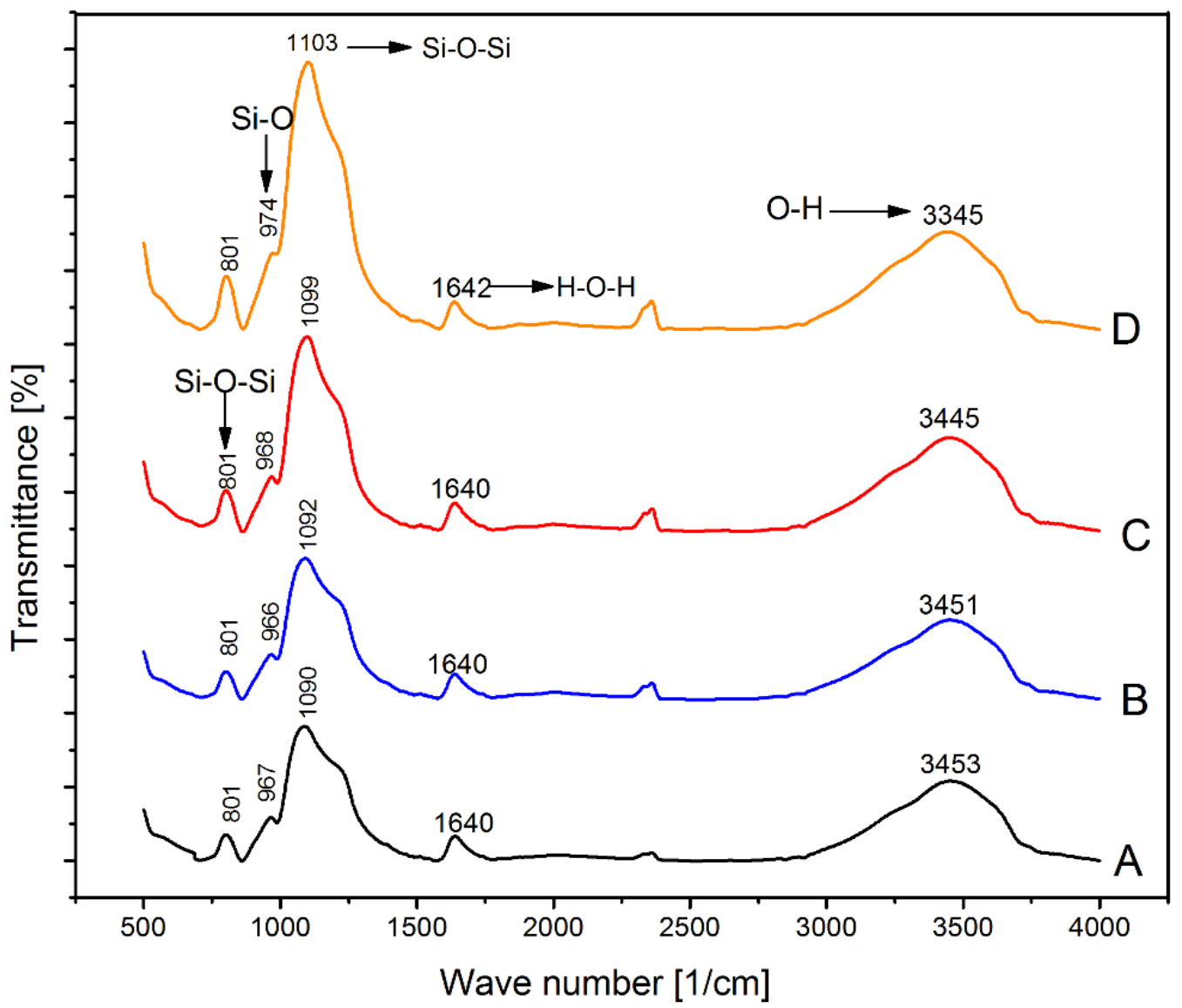

Fig.-4: FTIR Spectra of Silica SBA-15 Samples

Nowadays, the measurement of DSC analysis is the new analytical method for characterizing pore structure of SBA-15. Currently, study to determine their textural and structural quality properties ${ }^{37}$. DSC is a thermal analysis method which investigated transitions phase of materials, such as glass transition temperatures, melting point, boiling points, and heat flow within materials as a function of temperature also time. To obtain qualitative and quantitative data from the thermal analysis measurements are used about the physical and chemical changes of the thermal stability information from DSC measurement.

The DSC curve in Fig.-5 show two peaks, they are crystalline temperature and thermal glass transition temperature. Thermograms of samples were presented from thermal glass transition temperature at 69 to $74^{\circ} \mathrm{C}$ and one sharp fusion endothermic of the crystalline point at $158^{\circ} \mathrm{C}$. However, no melting peak of samples was shown in the DSC curve. The absence of melting point phase transition of samples in the DSC analysis is a signal that the samples have thermal stability at $250^{\circ} \mathrm{C}$ for 20 minutes. ${ }^{38,39}$

Presents an overview of the thermal analysis of silica SBA-15 samples. The experiment data from DSC measurement can be compared with the data in XRD pattern and FTIR spectra, in which that Sample D has the higher glass transition temperature and the lower of the requirement of heat to changes the phase from solid to rubber $(\mathrm{Tg})$. The significant increased of $\mathrm{Tg}$ may be attributed to the strong interaction of molecules silica precursor during hydrothermal treatment. Spectra IR is very strong at $1103 \mathrm{~cm}^{-1}$ with the presence of Si-O-Si. 

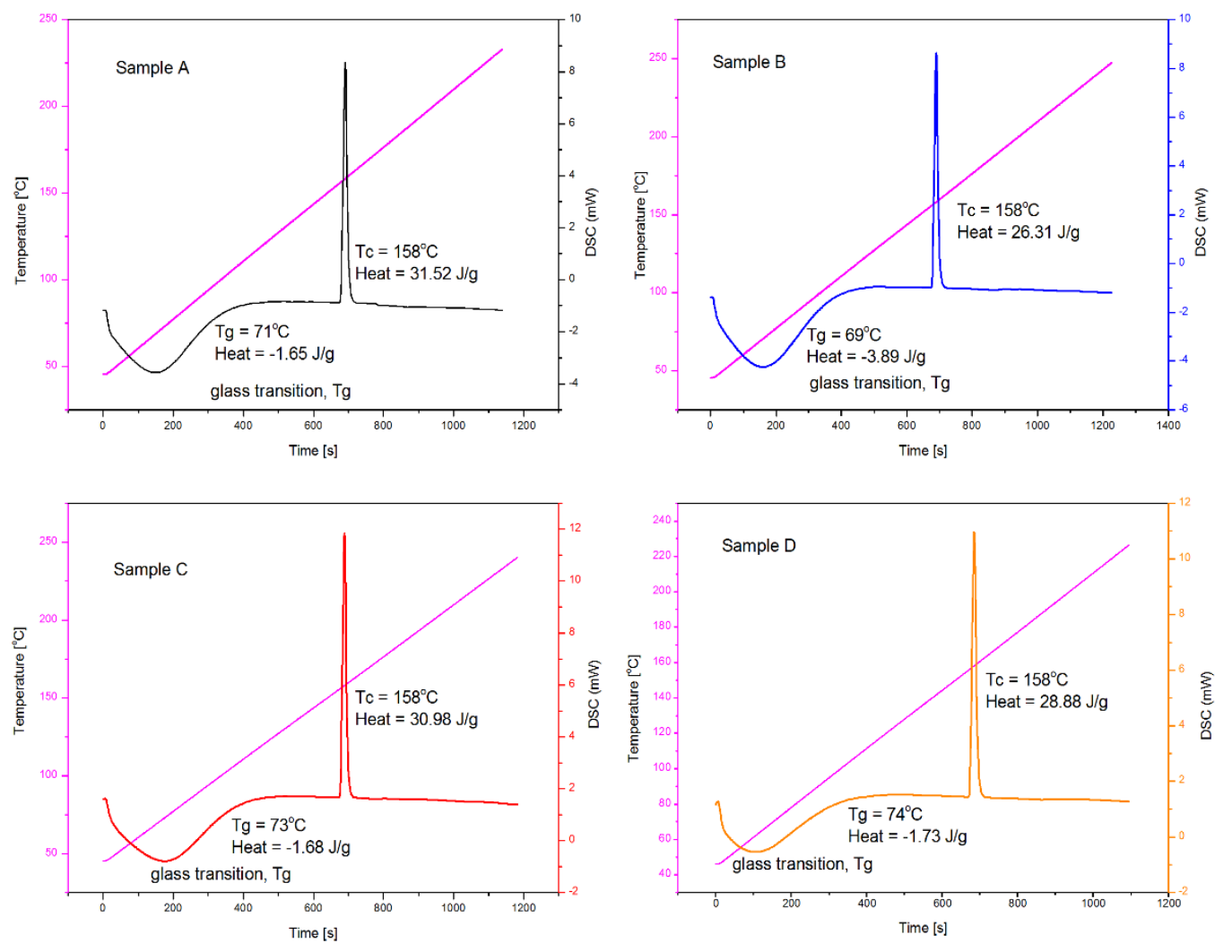

Fig.-5: The Thermal Profile of Silica SBA-15 Samples Using DSC Analysis

\section{CONCLUSION}

This study shows that physical adsorption analysis and the physicochemical properties SBA-15 were conducted to understand the effect of the temperature preparation of surfactant template and hydrothermal treatment. It is possible to synthesize mesoporous silica SBA-15 with pore size can be arrayed from 9 to $14 \mathrm{~nm}$, pore volume from 1.4 to $1.8 \mathrm{cc} \cdot \mathrm{g}^{-1}$ and surface area from 450 to $560 \mathrm{~m}^{2} \cdot \mathrm{g}^{-1}$. The physicochemical properties have near unchanged for the variation synthesized condition of silica SBA15. The large specific surface area, pore diameter, pore volume, mesostructure, and thermal stability can be supported for application in catalysis and storage.

\section{ACKNOWLEDGMENT}

We wish grateful for the financial support for a doctoral grant that supports the funding of this study from the Ministry of Research, Technology and Higher Education of Republic of Indonesia.

\section{REFERENCES}

1. K. Ishizaki, S. Komarneni, M. Nanko, Springer, Boston, MA, 181-201. (1998)

2. D. Zhao, J. Feng, Q. Huo, et al. Science, 279(1998)

3. R. Ouargli, N. Bouazizi, M. Khelil, et al. Chemical Physics Letters, 673(4), 30(2017), DOI: 10.1016/j.cplett.2017.01.073.

4. P. Thirumavalavan, V. Rajendran, R. Sivaraj. Oriental Journal of Chemistry, 34(5), 2367(2018). DOI: $10.13005 / \mathrm{ojc} / 340555$

5. V. V. Cotea, C.E. Luchian, N. Bilba, M. Niculaua. Analytica Chimica Acta, 732, 180(2012), DOI: 10.1016/j.aca.2011.10.019.

6. K. Ahmed, F. Rehman, C.T.G.V.M.T. Pires, et al. ,Microporous and Mesoporous Materials, 236, 167(2016), DOI: 10.1016/j.micromeso.2016.08.040. 
RASĀYAN J. Chem.

Vol. 12 | No. 3 |1117 - 1126| July - September | 2019

7. J. de O.N. Ribeiro, D.C.L. Vasconcelos, W.L. Vasconcelos, et al., Materials Research, 22(1), (2018), DOI: 10.1590/1980-5373-mr-2018-0651.

8. F. Rajabi, F. Fayyaz, R. Luque., Microporous and Mesoporous Materials, 253, 64(2017), DOI: 10.1016/j.micromeso.2017.06.043.

9. L. Washmon-Kriel, V.L. Jimenez, K.J. Balkus, Journal of Molecular Catalysis B: Enzymatic, 40(5), 10(2000), DOI: 10.1016/S1381-1177(99)00123-X

10. V.K. Tomer, S. Devi, R. Malik, S.P. Nehra, S. Duhan, Microporous and Mesoporous Materials, 219, (2016) DOI: 10.1016/j.micromeso.2015.08.016

11. M. Hosseini, V.K. Gupta, M.R. Ganjali, et al, Analytica Chimica Acta, 715(20), 80(2012), DOI: 10.1016/j.aca.2011.12.021.

12. M.H. Koh, S.A.H. Azaman, B.H. Hameed, A.T.M. Din, IOP Conference Series: Materials Science and Engineering, 206 (1), 012056(2017), DOI: 10.1088/1757-899X/206/1/012056.

13. R. Thahir, H. Bangngalino, A.W. Wahab, N.L. Nafie, I. Raya, IOP Conference Series: Material Science and Engineering, 509(124), 012124(2019), DOI: 10.1088/1757-899X/509/1/012124.

14. K. Ishizaki, S. Komarneni, M. Nanko (auth.), Materials Technology Series 4; Springer US, (1998).

15. L. Cao, M. Kruk, Colloids and Surfaces A: Physicochemical and Engineering Aspects, 357(1), 90(2010), DOI: 10.1016/j.colsurfa.2009.09.019

16. J.P. Thielemann, F. Girgsdies, R. Schlögl, C. Hess, Beilstein Journal of Nanotechnology, 2, 110(2011), DOI: 10.3762/bjnano.2.13.

17. K.S.W. Sing. ,Pure Applied of Chemistry, PAC, 57(4), 603(1985), DOI: 10.1351/pac198557040603.

18. M. Jaroniec, M. Kruk, J.P. Olivier, Langmuir, 15(16), 5410(1999), DOI: 10.1021/la990136e.

19. S. Kumar, M.M. Malik, R. Purohit, Materials Today: Proceedings, 4(2), 350(2017), DOI: 10.1016/j.matpr.2017.01.032

20. J.B. Condon, Elsevier Science, Amsterdam, 1-27, (2006)

21. S. Brunauer, P.H. Emmett, E. Teller, Journal of the American Chemical Society, 60(2), 309(1938), DOI: $10.1021 / \mathrm{ja} 01269 \mathrm{a} 023$

22. C. Lastoskie, K.E. Gubbins, N. Quirke, The Journal of Physical Chemistry, 97(18), 486(1993), DOI: $10.1021 / \mathrm{j} 100120 \mathrm{a} 035$.

23. K.S.W. Sing., Advances in Colloid and Interface Science, 76, 3(1998), DOI: 10.1016/S00018686(98)00038-4.

24. R.E. Morsi, R.S. Mohamed, Royal Society Open Science, 5(3), 17202(2018), DOI: 10.1098/rsos.172021

25. M. Su, H. Su, B. Du, et al., Korean Journal of Chemical Engineering, 32(5), 852-859(2015), DOI: 10.1007/s11814-014-0270-5.

26. Y. Dong, B. Lu, S. Zang, et al., Journal of Chemical Technology \& Biotechnology, 86(4), 616(2011), DOI: 10.1002/jctb.2559.

27. M. Popova, H. Lazarova, A. Szegedi, et al., Journal of Serbian Chemical Society, 83(1), 39(2018), DOI: $10.2298 / \mathrm{JSC} 170306071 \mathrm{P}$.

28. I. Akbartabar, M.E. Yazdanshenas, H.-A. Tayebi, N. Nasirizadeh, Iranian Journal of Health Sciences, 5(3), 17(2017), DOI: 10.29252/jhs.5.3.17.

29. Chapter 2 Pore structure of silica. In Journal of Chromatography Library; Unger, K. K., Ed.; Elsevier, 15-55, 16(1979)

30. I.W. Sutapa, A.W. Wahab, P. Taba, N.L. Nafie, Oriental Journal of Chemistry, 34(2), 1016(2018), DOI: $10.13005 / \mathrm{ojc} / 340252$.

31. M. Kokunešoski, Z. Baščarević, Z. Rakočević, et al., Science of Sintering, 111-121, 50 (1)(2018).

32. R. Nandanwar, P. Singh, F. Haque, American Chemical Science Journal, 5(1), 1(2015), DOI: 10.9734/ACSJ/2015/10875.

33. R.A. Bakar, R. Yahya, S.N. Gan, Procedia Chemistry, 18, 189(2016), DOI: 10.1016/j.proche.2016.03.092.

34. H. Kusumastuti, W. Trisunaryanti, I. Izul Falah, M. Fajar Marsuki, Rasayan Journal of Chemistry, 11(2), 522(2018), DOI: 10.31788/RJC.2018.1122061. 


\section{RASĀYAN J. Chem.}

Vol. 12 | No. 3 |1117 - 1126| July - September | 2019

35. H. Chaudhuri, S. Dash, A. Sarkar, Journal of Environmental Chemical Engineering, 3(4), 2866(2015), DOI: 10.1016/j.jece.2015.10.009.

36. D. Dutta, S. Ghosh, Rasayan Journal of Chemistry, 11(3), 1018(2018), DOI: 10.31788/RJC.2018.1133046.

37. B. Charmas, J. Skubiszewska-Zięba, Journal of Thermal Analysis and Calorimetry, 129(1), 23(2017), DOI: 10.1007/s10973-017-6126-6.

38. Y. Zhang, Z. Zhi, T. Jiang, et al., Journal of Controlled Release, 145(3), 257(2010), DOI: 10.1016/j.jconrel.2010.04.029.

39. B. Prince Raja D, B. Stanly Jones Retnam, A. Samuel Prabu G, A. Sundaram A., Rasayan Journal of Chemistry, 11(3), 990(2018), DOI: 10.31788/RJC.2018.1133048.

[RJC-5306/2019] 